\title{
Use of Pre- and Post-Museum Visit Classroom Activities by Kindergarten - Eighth Grade Teachers
}

\author{
Julie A. Holmes \\ Louisiana Tech University
}

\begin{abstract}
Informal learning settings have been shown to improve student achievement. The positive effects of museum-based learning may be increased if content knowledge activities are included before visiting the museum and if post-visit activities are planned to build upon the museum experience. The purpose of this study was to examine the use of classroom activities before, during, and after a visit to a science museum. Teachers were given a 17 item forced response selfreport instrument to complete that was designed by the researcher. Data analysis revealed more use of previsit activities than post-visit activities. Recommendations are made for further research and future practice.
\end{abstract}

\section{Introduction}

Most American students are not excited about science, according to Ye, Wells, Talkmitt, and Ren [13]. These researchers investigated and compared American and Chinese secondary student achievement, their attitudes toward science, and various other factors that may contribute to their science learning. The results that are pertinent to this study showed that American students take science classes because they are required, dislike science because of too much memorization, and find the mathematics in science to be difficult. The reason that students feel this way about science is due, in part, to the methods that teachers use to teach science as well as to their poor science background knowledge [8]. Hoff [9] stated that teaching science by memorizing facts and vocabulary words is inappropriate because students are not required to connect this knowledge into a cohesive picture of how the world works and how we come to know it. Havasy [8] also claimed that science education to most adults was synonymous with passive learning and memorization.

So, how do teachers get students interested and motivated to learn science? Havasy [8] stated, "We need a revolution in the way we teach science" (p. 49). She suggested that to increase learning in science, teachers need to give students a reason to want to learn science. Connections need to be made between science and the world in which students live, or, in other words, science needs to be related to the students' real world experiences. When science is practical, it is more dynamic and memorable to students.

The revolution that Havasy [8] alluded to is inquiry-based learning in science. She noted that the same information that is taught using traditional teaching methods can be taught, often more effectively, through inquiry-based learning. Not only does student achievement improve in science when using inquiry-based teaching methods, but interest and motivation are also stimulated [5], [6]. Inquiry-based learning guides students' natural curiosity by encouraging investigation and discovery. This, in turn, can make science relevant in students' lives.

Alternative learning environments other than the classroom also need to be considered by teachers. Science museums and other informal learning settings have been shown to improve student achievement [3]. Informal learning settings, such as aquariums, museums, and zoos, can provide teachers with another venue in which to not only improve student achievement, but to support interest in an area of study, and to develop motivation to learn more about a particular subject. Often these types of settings are considered an afterthought in the education reform movement, although they are viewed as valuable public education environments, according to Bartels. 
This is, he stated, "a case of missed opportunity" [3]. In terms of science museums in particular, Bartels claimed that they support inquiry-based learning and a shift in students' and teachers' attitudes 'from a third person relationship (science that others do), to a first person relationship (science that I can do)" [3]. Informal science institutions also have unique features that make them advantageous to educational reform, such as promoting science in an accessible form, creating direct experiences, and providing support for teachers. Science centers also can be considered as an "integral part of global educational infrastructure" [1]. In a survey conducted of its members in 2000, the Association of Science and Technology Centers (ASTC) found that of the 169 museums reporting data, 17 million schoolchildren were served each year through field trips and outreach programs. These experiences are planned by teachers in order to produce "museumbased learning” or museum education; the learning that takes place through a visit to a museum [4].

Field trips to a museum can be thought of as an endeavor to increase learning by changing the learning setting. However, other factors may detract from the intended goal of learning, such as the novelty of the setting [12], an overwhelming number of exhibits to absorb [2], and only having one brief visit to learn multiple concepts from the setting [10]. The positive effects of museum-based learning may be increased if content knowledge activities are included before visiting the museum and if post-visit activities are planned to build upon the museum experience [7]. The activities for use before a museum visit can act as an advance organizer to focus the students' attention on the museum exhibits of interest and help them attend to the most important aspects of the museum visit [10]. Holmes also noted that post-visit activities should be planned (a) in light of what the students experienced when they visited the museum to reinforce concepts learned at the museum site, (b) to allow sharing with the entire class what they experienced with particular exhibits and (c) to address any misconceptions about scientific concepts that the students may have expressed during the museum visit.

\section{Methodology}

The purpose of this study was to examine the use of classroom activities before, during, and after a visit to Louisiana Tech University's children's mathematics and science museum called the IDEA Place. The IDEA Place (Investigate, Discover,
Explore, Ask) was approved by the Louisiana Board of Regents in 1991 as part of Louisiana Tech University's science and technology education center (SciTEC). The IDEA Place opened in April 1994, and since then more than 80,000 K-12 students from north Louisiana and Arkansas have visited the IDEA Place. Attendance has grown steadily each year, with an anticipated 2012-2013 school year attendance approaching 10,000. Through the SciTEC program, other science and technology resources are available. The IDEA Place in 2002 assumed the management responsibility for the university's Planetarium, which was upgraded from a Level 2 to a Level 5 facility after a $\$ 90,000$ renovation project during the Summer of 2002 that enhanced and modernized the it by allowing the projection of images of the sun, moon, planets, and 3,000 visible stars. Also, the IDEA Place has housed the NASA Educator Resource Center (ERC) for Louisiana since 1999. The ERC provides teachers with free resource materials from NASA, such as posters, educator guides, and CD-ROMs. ERC staff members are also available for classroom presentations and professional development workshops for teachers.

The participants were 34 Kindergarten-eighth grade teachers from public and private schools in North Louisiana and southern Arkansas that participated in the annual IDEA Place Space Days program at Louisiana Tech University. Approximately $47 \%$ of the teachers taught Kindergarten through third grade, while $50 \%$ of the teachers indicated teaching fourth through eighth grades. The remaining participants indicated they held school positions other than as a regular classroom teacher (computer lab monitor, curriculum coordinator). These teachers possessed a vast range of years of teaching experience, from first year teachers to those with 28 years of experience; nine of the 34 participants have taught one to five years $(26.4 \%)$ and 20 participants indicated having taught for more than five years (58.8\%; some participants did not respond to this question). All teachers that brought classes to the IDEA Place Space Days program were given the opportunity to participate in the study.

Teachers were given a 17 item forced response self-report instrument to complete that was designed by the researcher. This survey allowed the teachers to indicate with a yes or no answer the activities they had completed with their students prior to the museum visit, if their students had structured activities assigned by them to complete during the visit, and what activities they had planned to complete after the visit. The following areas were surveyed for pre-visit use: 
(a) review of school field trip rules, (b) review of IDEA Place rules, (c) reading books about topics related to the museum visit, (d) completion of writings about topics related to the field trip, (e) completion of art activities related to the trip, (f) completion of science experiments that correlated with the museum visit, (g) use of videos and DVDs about science, and (h) use of computer assisted activities (such as webquests) that built prior knowledge before the field trip. One question asked teachers to indicate with a yes/no response if they had a learning activity assigned by them for the students to complete during their visit to the museum. Post-visit items that were surveyed included discussing the events experienced during the field trip as well as the items $\mathrm{c}$ through $\mathrm{h}$ listed above. An open response section was also included at the end of each section of the survey. This allowed the teachers to explain in detail those activities that they had actually completed with their students, as well as other pertinent topics that were addressed that did not specifically fit within the question prompts. Teachers were also allowed the opportunity to express what activities they felt that their students enjoyed the most and for any comments that could improve the events for the next year. For the purposes of this study, only the use of classroom activities before, during, and after a visit to a science museum will be reported.

The IDEA Place Space Days program has occurred each spring for nine years. The event has grown from one day to an entire week in 2004. Teachers are scheduled to rotate their classes through four one-hour long activity blocks. One block is a planetarium show. One block is a presentation by the aviation students attending Louisiana Tech University about studying to be a pilot. Another block consisted of a visit to the IDEA Place Experiment Gallery. The Experiment Gallery consists of more than 25 interactive exhibits based on five theme areas: (a) electricity, (b) light and optics, (c) mechanics, (d) sound and waves, and e) weather. The Experiment Gallery also contains an Activity Station. This area provides visitors the opportunity to experience fun hands-on science activities supervised by the IDEA Place staff. Teachers are able to select from activities in which they would like their classes to participate prior to their visits, and new activities are introduced through lessons developed by preservice teachers. The Experiment Gallery also houses a resource center for teachers to provide additional materials and support to correlate classroom activities with a visit to the Experiment Gallery. Additionally, on-line resources have been developed as another resource for teachers to utilize fully the Experiment Gallery to promote student achievement in science. Finally, the last block was an outdoor activity time with interactive displays from local businesses and community service partners, such as the fire department and the police department. Inflatable bouncers were also provided for the students to play in and a free lunch was served and sponsored through local merchant donations and by the IDEA Place.

\section{Data Analysis}

Frequency distributions were computed for the items in the three sections of the survey (pre-visit activities, during visit activities and post-visit activities). These data appear in the tables that follow.

\subsection{Pre-visit activities and activities completed during the museum visit}

Table 1 shows the percentages of teachers that completed various activities with their students prior to the visit to the IDEA Place Space Days. This table also indicates the percentage of teacher responses to the item on the survey that asked if their students had a structured activity to complete during the trip to the science museum. A structured activity was considered to be something for the students to complete at the museum site that was assigned by the teacher. This could have been a worksheet, drawing of their favorite exhibit, or other assignment that was to be completed on site during the Space Days field trip.

As shown in Table 1, all teachers reviewed school rules and a majority reviewed museum rules prior to the visit. A majority of the respondents also indicated that they had read books to their students in preparation for the science museum visit. In the open response section, teachers indicated specific materials read by the students, such as Scholastic News, stories, and textbook readings about space. Many also disclosed that they had their students watch videos or DVDs about space and science topics before coming to the science museum. Two respondents directly referred to using videos from United Streaming. More than half of the teachers indicated their students wrote about space related topics. Teachers stated in the open response section that their students wrote facts about the planets, constructed concept maps, and wrote paragraphs or stories about space. Approximately half of the participating teachers had their students perform 
science experiments before a science museum visit. Experiments about floating and participation in the Barksdale Air Force Base program called STARBASE were indicated in the open response section as science experiments done prior to the field trip. Art projects and computer-assisted activities were used less frequently by the participants in the study. Those teachers who indicated completing these types of activities mentioned color sheets and drawing about an imaginary trip into space for art-related activities. One teacher indicated using computer activities that are referenced within the Louisiana Comprehensive Curriculum for her grade level.

Table 1.

Descriptive analysis of pre-visit activities and activities completed during the museum visit

\begin{tabular}{|l|l|l|l|}
\hline Activity & Yes & No & $\begin{array}{l}\text { Did not } \\
\text { respond }\end{array}$ \\
\hline $\begin{array}{l}\text { Review of school } \\
\text { rules }\end{array}$ & $100.0 \%$ & $0.0 \%$ & \\
\hline $\begin{array}{l}\text { Review of IDEA } \\
\text { Place rules }\end{array}$ & $97.0 \%$ & $3.0 \%$ & \\
\hline $\begin{array}{l}\text { Read books about } \\
\text { space/science }\end{array}$ & $76.5 \%$ & $23.5 \%$ & \\
\hline $\begin{array}{l}\text { Completed writings } \\
\text { about space/science }\end{array}$ & $61.8 \%$ & $38.2 \%$ & \\
\hline $\begin{array}{l}\text { Completed art } \\
\text { activities about the } \\
\text { trip }\end{array}$ & $44.2 \%$ & $55.8 \%$ & \\
\hline $\begin{array}{l}\text { Completed related } \\
\text { science experiments }\end{array}$ & $58.8 \%$ & $41.2 \%$ & \\
\hline $\begin{array}{l}\text { Watched about } \\
\text { videos/DVDs about } \\
\text { space/science }\end{array}$ & $76.5 \%$ & $17.6 \%$ & $5.9 \%$ \\
\hline $\begin{array}{l}\text { Completed } \\
\text { computer-assisted } \\
\text { activities }\end{array}$ & $41.2 \%$ & $58.8 \%$ & \\
\hline $\begin{array}{l}\text { Structured activities } \\
\text { to complete during } \\
\text { the museum visit }\end{array}$ & $20.6 \%$ & $76.5 \%$ & $2.9 \%$ \\
\hline
\end{tabular}

\subsection{Activities completed during the museum visit}

Table 1 also indicates the percentage of teacher responses to the item on the survey that asked if their students had a structured activity to complete during the trip to the science museum. A structured activity was thought to be by the researcher some sort of assignment given by the teacher for the students to complete while they were at the museum. A small percentage of the teachers indicated that their students had a structured activity to complete during the museum visit; however in the open response section, when prompted to explain a yes answer to this question, only one teacher defined an activity that would clearly be considered as a learning activity completed on-site. A first grade teacher responded that her class wrote a paragraph about the experience during the trip. In a similar study four years earlier [11], a similar question was posed to the participating teachers. In discussions with these teachers while they were attending Space Days, the researcher noted that some teachers perceived the "structured activity" for their students to be the schedule of events that they were to follow to rotate through all four of the activities planned for the Space Days participants. The question was rephrased for the survey used in the current study. It is believed by the researcher that this question is still somewhat misunderstood. Therefore, these data still seem to be clouded in terms of what the researcher was really looking for in the teachers' response to this item.

\subsection{Post-visit activities}

Table 2 displays the frequencies of the use of various classroom activities and class discussions after the teachers brought their students to the Space Days events. These were to be completed within several days of the field trip.

As shown in Table 2, the teachers indicated less use of almost all of the activities listed above after the students had experienced the field trip. A greater use of writing after the visit is noted in the data analysis. This could be because the students would have a concrete experience to write about. Teachers indicated that students wrote essays about the video shown in the Planetarium and on other topics, If I Went Into Space, thanks you notes, and journal assignments. One teacher indicated that the class had a "Trucker Buddy" that they wrote a letter to about their field trip to the IDEA Place. Teachers indicated slightly less use of art activities after the museum visit. In the open response section, one teacher wrote that the class constructed a model of the solar system as an art project. It is interesting to note that there was less use of books, videos/DVDs, science experiments, and computerassisted activities as indicated by the participating teachers. Teachers that did implement activities in 
these categories mentioned conducting experiments on magnetism and light, computer research on related topics, and using a series of books about space.

Table 2.

Descriptive analysis of post-visit activities

\begin{tabular}{|l|l|l|l|}
\hline Activity & Yes & No & $\begin{array}{l}\text { Did not } \\
\text { respond }\end{array}$ \\
\hline $\begin{array}{l}\text { Class discussion of } \\
\text { the events } \\
\text { experienced during } \\
\text { the trip }\end{array}$ & $85.3 \%$ & $14.7 \%$ & \\
\hline $\begin{array}{l}\text { Read books about } \\
\text { space/science }\end{array}$ & $38.2 \%$ & $61.8 \%$ & \\
\hline $\begin{array}{l}\text { Complete writings } \\
\text { about art } \\
\text { space/science topics }\end{array}$ & $67.6 \%$ & $29.4 \%$ & $3.0 \%$ \\
\hline $\begin{array}{l}\text { Complete about } \\
\text { activities } \\
\text { the trip }\end{array}$ & $32.4 \%$ & $67.6 \%$ & $2.9 \%$ \\
\hline $\begin{array}{l}\text { Complete related } \\
\text { science } \\
\text { experiments }\end{array}$ & $47.1 \%$ & $52.9 \%$ & \\
\hline $\begin{array}{l}\text { Watch } \\
\text { videos/DVDs about } \\
\text { space/science }\end{array}$ & & $70.6 \%$ & \\
\hline $\begin{array}{l}\text { Complete computer- } \\
\text { assisted activities }\end{array}$ & $29.4 \%$ & \\
\hline
\end{tabular}

The teachers noted several different topics that their classes completed as a result of the visit to the IDEA Place during Space Days. One teacher indicated that they planned another trip to a related museum for further study. Two teachers indicated having discussions with the class about career choices related to space and flight. Several mentioned discussing females in the field of space flight and conducted further research in this area and discussed Amelia Earhart's life. One other teacher noted that the class constructed a photo album of pictures from their visit.

\section{Conclusions and Recommendations}

The data analysis indicates that most teachers at all grade levels reviewed school and museum rules prior to the visit, and they completed at least one classroom activity in preparation for the science museum visit. While the analysis revealed that the teachers felt they had structured activities for their students to complete during the visit to the Space Days events, this did not coincide with the definition of "structured activity" as thought of by this researcher. The activities conducted after the museum visit, as indicated by the participants, were less in number in five of the six categories than those activities completed prior to the field trip. A slight increased use of writing activities was revealed; however, there was less use of books, videos and DVDs, art projects, science experiments and computer assisted activities.

Recommendations for future practice would be for museums to provide teachers with activities to complete in conjunction with the museum visit, hopefully before and after the planned event. It appears that the positive effects of museum-based learning might be increased if prior content knowledge activities are included before visiting the museum and if planned post-visit activities would build upon the museum experience. These factors were found to be important in other research [7].

Many museums have realized the importance of the aforementioned research by providing resources on line for teachers to use in conjunction with their planned field trips. The IDEA Place has also made available resources for the exhibits in the museum. How well are these resources being utilized? This would be interesting to study for further research. Professional development activities and workshops could also be developed to make teachers aware of the importance of including pre- and post- museum visit activities in the classroom and introducing them to the variety of resources that most museums and other informal learning settings have available for their use.

As mentioned earlier, other factors may detract from the intended goal of learning, in science museums. One such factor is novelty of the setting, as noted by research by Martin, Falk, and Balling [12]. In this study, the goal was to analyze the effects of a novel environment on behavior on a field trip. The study was designed to compare the learning and behavior of participants in novel or familiar settings. A total of 63 participants, ranging in age from 10 to 13, were included in the study. Of them, 33 participants (14 females and 19 males) had been in the program in previous years and were defined as the repeater group. The remaining 30 participants (10 females and 20 males) had not participated in the program before, and thus, comprised the novice group. Overall, the participants showed a reduction of conceptual learning in the novel setting as compared to the familiar setting. The participants did show a significant increase in 
knowledge of the novel setting, although the researchers noted that the effect was not strong. The repeater group showed a strong effect for overall concept learning, and demonstrated similar amounts of task-related concept learning in both environments.

This study indicates the importance of "prompting" the students about the museum environment prior to the field trip to lessen the novelty effect. It would be important for museums to provide resources for teachers to "introduce" the museum to the students, such as having staff available to visit the classroom prior to the museum visit and present a program on what the class will experience when they come to the facility. Another suggestion would be for museums to create virtual field trip introductory activities that teachers could access on line to help lessen the novelty effect.

Another factor in making museum-based learning more effective is to consider the overwhelming number of exhibits the students are expected to absorb in one short visit [2], [10]. Teachers should plan to isolate certain areas of a museum facility for the students to explore in depth, especially if the facility is large and has many exhibits. The students may be overwhelmed if expected to gain conceptual knowledge from too many exhibits at one time. Repeated visits could be planned to focus upon other exhibit areas of interest.

Teachers also should visit the museum before the class visit and plan appropriate activities to be completed during the museum visit in order to maximize the learning potential of the museum experience. This initial visit by the teacher can help in planning activities that will assist in building prior knowledge in their students and to focus and improve concept knowledge attainment at the museum. The teachers in this study were not asked how closely the pre-visit or post-visit activities correlated with the exhibits and activities experienced during Space Days. Further research is needed in this area.

Other benefits can be noted for the teacher to conduct a visit to the museum prior to brining his/her class to the facility. Teachers could plan for the class to visit only displays and exhibits of interest in conjunction with what the class is studying back in the classroom. This will help to focus attention to certain exhibits of interest to correlate what is being learned back at school with what is experienced at the museum, instead of expecting the students to learn something from every single exhibit, as previously mentioned. This teacher visit could also be used to plan multiple visits, targeting other areas of interest as content is taught in the regular classroom.

Another interesting topic for further research would be how the teachers selected the types of activities they chose to complete with their students. It was noted earlier that post-visit activities should be planned in light of what the students experienced to reinforce concepts, to allow sharing with the entire class what they experienced, and to address any misconceptions about scientific concepts that the students may have expressed during the museum visit [10]. Are teachers considering these factors in their selection of activities? Semi-structured interviews with selected participants in future studies would help address this question.

Visits to informal learning settings have been shown to be effective learning tools in many research studies [3], [4], [7]. The addition of pre- and post-visit activities that are well planned and correlate with the events to be experienced during the field trip will help teachers to make these incidents what teachers really want them to be: learning experiences.

\section{References}

[1] Association of Science and Technology Centers, "Highlights from the ASTC Sourcebook of Science Center Statistics 2001", retrieved from http://www.astc.org/pubs/sourcebook_2001.htm, July 13, 2002.

[2] J. Balling and J. Falk, "A Perspective on Field Trips: Environmental Effects on Learning", Curator, 1980, pp. 229-240.

[3] D. M. Bartels, “On-Site Science: Why Museums, Zoos, and Other Informal Classrooms Need to be a Bigger Part of the Reform Equation", Education Week, September 19, 2001, pp. 45.

[4] M. Borun, "Planets and Pulleys: Studies of Class Visits to Science Museums", ERIC Document Reproduction Service No. 267 965, 1983.

[5] J. T. Fouts and R. E. Myers, "Classroom Environments and Middle School Students' Views of Science”, Journal of Research in Science Teaching, 1992, pp.356-361.

[6] M. P. Freedman, "Relationship Among Laboratory Instruction, Attitude Toward Science and Achievement in Science Knowledge”, Journal of Research in Science Teaching, 1997, pp. 343-357. 
[7] J. Gilbert and M. Priest, "Models and Discourse: A Primary School Science Class Visit to a Museum”, Science Education, 1997, pp. 749-762.

[8] R. A. D. Havasy, "Getting a Clue: We Need a Revolution in the Way We Teach Science", Education Week, November 7, 2001, pp.49.

[9] D. J. Hoff, “Progress Lacking on US Students' Grasp of Science. Education Week, November 28, 2001, pp. 1, 14.

[10] J. A. Holmes, "Museum-Based Learning; Informal Learning Settings and their Role in Student Motivation and Achievement in Science", Dissertation Abstracts International, 2003, pp. 846.

[11] J. A. Holmes, "Use of Pre- and Post-Visit Classroom Activities with Informal Learning Settings”, paper presented at the Annual Meeting of the Mid-South Educational Research Association, Gatlinburg, Tennessee, 2004.

[12] W. W. Martin, J. H. Falk, and J. D. Balling, "Environmental Effects on Learning: The Outdoor Field Trip”, Science Education, 1981, pp. 301-309.

[13] R.Ye, R. R. Wells, S. Talkmitt, and H. Ren,(1998).

"Student attitudes toward science learning: A cross-national study of American and Chinese secondary school students", paper presented at the National Science Teacher Association National Convention, Las Vegas, Nevada, 1998. 